\title{
Common bile duct schwannoma: A case report and review of literature
}

\author{
Luigi Fenoglio, Sara Severini, Paola Cena, Elena Migliore, Christian Bracco, Fulvio Pomero, Sergio Panzone, \\ Giovan Battista Cavallero, Alberto Silvestri, Rodolfo Brizio, Felice Borghi
}

Luigi Fenoglio, Sara Severini, Paola Cena, Elena Migliore, Christian Bracco, Fulvio Pomero, Sergio Panzone, Giovan Battista Cavallero, Alberto Silvestri, Department of Internal Medicine, Santa Croce and Carle Hospital, Cuneo, Italy

Rodolfo Brizio, Department of Pathology, Santa Croce and Carle Hospital, Cuneo, Italy

Felice Borghi, Department of General Surgery, Santa Croce and Carle Hospital, Cuneo, Italy

Correspondence to: Dr. Luigi Fenoglio, Santa Croce Hospital, Via Michele Coppino 26, Cuneo12100,

Italy. fenoglio.1@ospedale.cuneo.it

Telephone: +39-338-5064398 Fax: +39-171-641615

Received: 2006-11-14 Accepted: 2007-02-12

\begin{abstract}
Schwannoma is a myelin sheath tumor complicated with neurofibroma, neurofibromatosis and neurogenic sarcoma. Peripheral nerve sheath tumors represent $2 \%-6 \%$ of gastrointestinal tract stromal tumors (GIST), but there are deficient data about location of neurogenic tumors in the biliary system and only nine cases of schwannoma of the extrahepatic biliary tract have been reported. These tumors are clinically non-specific. They are usually symptomatic by compressing the close or adjacent structures when being retroperitoneal, and their preoperative diagnosis is extremely difficult. This paper reviews the literature data and describes a case of schwannoma of the common bile duct associated with cholestasis in a healthy young woman, diagnosed and treated in our department. This case is of interest on account of the complexity of its diagnosis and the atypical macroscopic growth pattern of the tumor.
\end{abstract}

Key words: Schwannoma; Neurinoma; Common bile duct; Biliary tract

(c) 2007 The WJG Press. All rights reserved.

Fenoglio L, Severini S, Cena P, Migliore E, Bracco C, Pomero F, Panzone S, Cavallero GB, Silvestri A, Brizio R, Borghi F. Common bile duct schwannoma: A case report and review of literature. World J Gastroenterol 2007; 13(8): 1275-1278

http://www.wjgnet.com/1007-9327/13/1275.asp

\section{INTRODUCTION}

Myelin sheath tumors comprise schwannoma, neu- rofibroma, neurofibromatosis and neurogenic sarcoma. More than $90 \%$ are benign ${ }^{[1]}$ and present in young to middle-aged subjects (twice in women than in men). They are usually asymptomatic and hence discovered incidentally ${ }^{[2]}$. Schwannoma is more common than neurofibroma. Its origin is often single. The $10 \%$ with a multiple origin ${ }^{[3]}$ are classified as neurofibromatosis II, a disorder of autosomal dominant inheritance ${ }^{[4]}$. When located in gastrointestinal tract, schwannoma, leiomyoma, leiomyosarcoma and leiomyoblastoma constitute the gastrointestinal stromal tumors (GIST) ${ }^{[5]}$. Peripheral nerve sheath tumors account for $2 \%-6 \%$ of the GIST, but there are few reports of neurogenic tumors in the biliary system. The retroperitoneum is rarely involved ${ }^{[6]}$. Schwannomas arise only occasionally in the extrahepatic ducts and provoke symptoms by compressing adjacent structures ${ }^{[7]}$. Their symptoms were so varied to make their preoperative diagnosis very difficult. A cholestatic syndrome in a healthy woman is described in this report.

\section{CASE REPORT}

The patient was a 41-year-old woman who presented with ingravescent pruritus lasting one month, a $4 \mathrm{~kg}$ weight loss and scleral subicterus. Her clinical and family history were devoid of significance. There was no history of drug intake. The physical examination evidenced a normal spleen and the absence of lymphadenopathies in the explorable sites. There was evidence of diffuse scratching lesions on the lower limbs and subicteric sclerae.

Laboratory results: RBC $4.49 \times 10^{6} / \mathrm{L}$ (4.2-5.4), WBC $4.76 \times 10^{3} / \mathrm{L}(4-10)$, hemoglobin $14.4 \mathrm{~g} / \mathrm{dL}$ (12-16), ESR $21 \mathrm{~mm} / \mathrm{s}$, PCR $0.76 \mathrm{mg} / \mathrm{L}(<3)$, LDH $412 \mathrm{U} / \mathrm{L}$ (313-618), total proteins $8.7 \mathrm{~g} / \mathrm{dL}(6.3-8.2)$, total bilirubin $2.1 \mathrm{mg} / \mathrm{dL}$ (0.2-1.3), conjugated bilirubin $1.4 \mathrm{mg} / \mathrm{dL}(0-0.4)$, bile acids $6.8 \mu \mathrm{mol} / \mathrm{L}(0-6)$, AST $90 \mathrm{U} / \mathrm{L}(<40)$, ALT $161 \mathrm{U} / \mathrm{L}(9-56)$, GGT 290 U/L (12-58), ALPh 192 U/L (38-126), amylase $60 \mathrm{U} / \mathrm{L}$ (30-110), antimitocondrial antibody negative, CEA $1.3 \mathrm{ng} / \mathrm{mL}(<5)$, CA $19-948.5 \mathrm{U} / \mathrm{mL}(<37)$, CA-125 $39.6 \mathrm{U} / \mathrm{mL}(<35)$.

A CT scan (Figure 1A) revealed a lesion between the head of the pancreas and the gall bladder infundibulum near to the middle segment of the common bile duct. The mass was heterogeneous with a diameter of $3 \mathrm{~cm}$. The upstream bile ducts were slightly dilated. The gall bladder was overdistended and contained a $2 \mathrm{~cm}$ stone in the fundus. Cholangio-MRI with the secretin test (Figure 1B-D) dislcosed a hypointensive signal in the weighted 


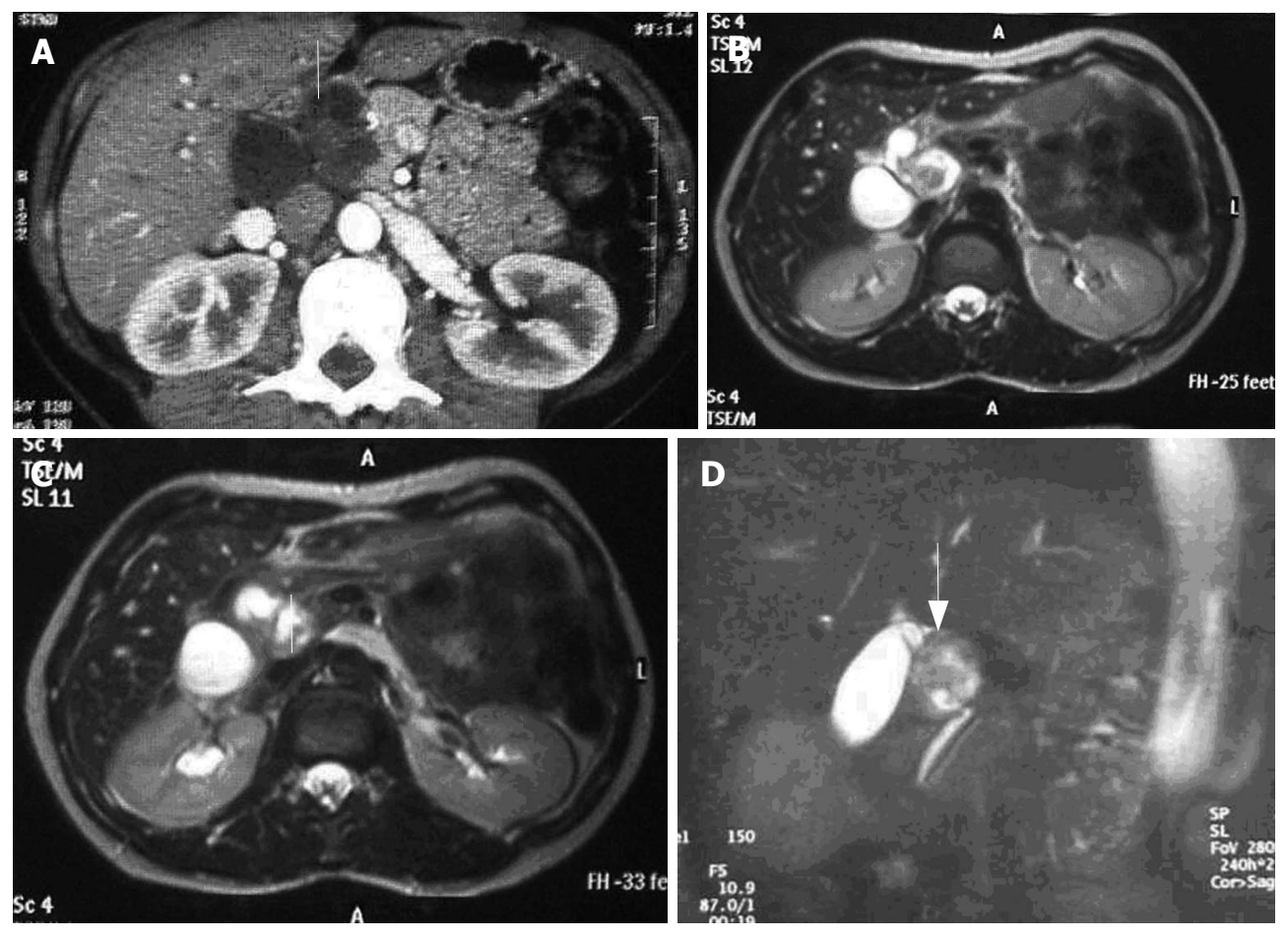

Figure 1 A: CT scan showing a very heterogeneous formation with a liquid content in close contiguity to the $\mathrm{CBD}$ (white arrow); B, C, D: CholangioMRI reveals a solid formation with a hypointensive signal in the weighted $\mathrm{T} 1$ sequences at the pancreatic isthmus (white arrows) with dilation of the upstream bile ducts.
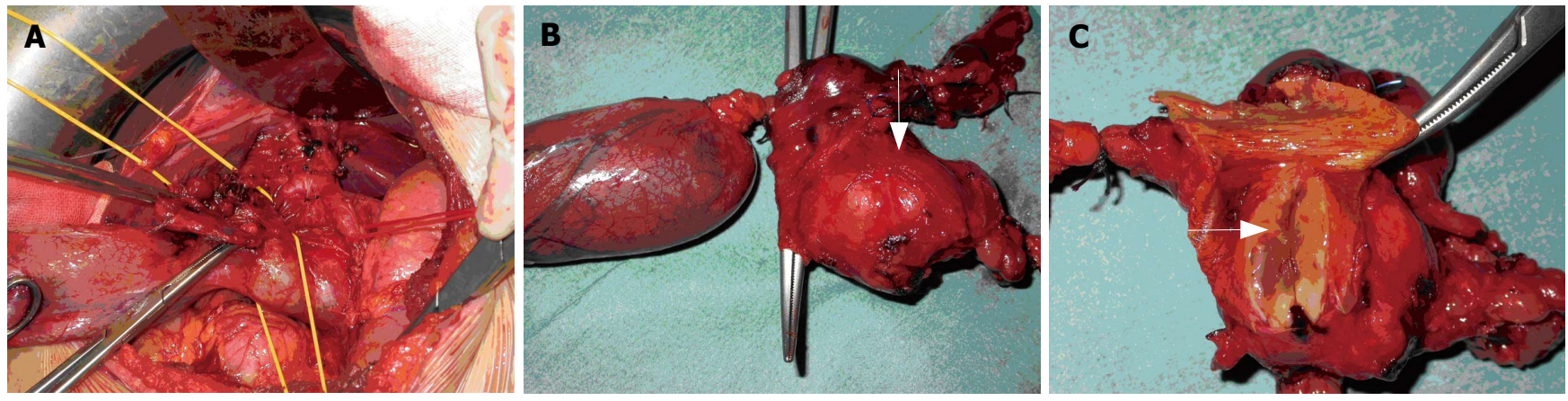

Figure 2 Intraoperative view of involvement of the intermediate tract of the common bile duct between its confluence with the cystic duct (A) and the prepancreatic tract (B) and (C) Gross inspection showing that the lesion (arrows) is solid and situated intramurally and below the mucosa in close contiguity with the CBD.

T1 sequences. The mass was assigned to the pancreatic isthmus. Its size and lack of uniformity were confirmed and a neoplastic origin was suspected. A good response to secretin showed that the function of the pancreas was unimpaired. Biliopancreatic echoendoscopy ruled out involvement of the pancreas, confirmed distention of the gall bladder and disclosed a solid, non-vascularised formation with many anaechogenic areas. Its contiguity with the portal axis rendered percutaneous biopsy inadvisable and exploratory laparotomy was performed. The formation involved the intermediate tract of the common bile duct between its confluence with the cystic duct and the prepancreatic tract (Figure 2A). The middle segment of the common bile duct was resected, together with the gall bladder (overdistended, but uninflamed) and the lymph nodes. A bilio-digestive Roux-en-Y anastomosis was performed on the loop. Gross inspection showed an intramural lesion under the mucosa with a diameter of 4 $\mathrm{cm}$ (Figure 2B and C). Histological examination revealed the proliferation of interwoven bundles of fused cells, occasionally separated by slacker, oedematous areas with a pseudocystic appearance (Figure 3A). There were also a few cells with an hyperchromic, atypical and bizarre nucleus (Figure 3B), ectatic, congested and partially thrombosed vessels (Figure 3C), and signs of perivascular hyalinisation (Figure 3D).

Immunohistochemical investigation showed that the tumor cells were vimentin and protein S-100 positive, and alphaactin, desmin, CD34, cytokeratin pan (clone ARE1/E3) and CD117 negative. The postoperative course was uneventful. The cholestatic and hepatic cytolytic indices normalised after two months, with definite disappearance of pruritus, which continue to be normal after one year .

\section{DISCUSSION}

Schwannoma of the bile ducts is particularly rare, and it usually arises in the head, neck, spinal cord and the extremities ${ }^{[8]}$, but rarely in retroperitoneum $(6 \%$ of primary retroperitoneal tumors $)^{[9]}$. It is usually located in the paravertebral regions or in the pre-sacral pelvic zone $e^{[2,10]}$. The bladder and abdominal wall are occasionally involved. 

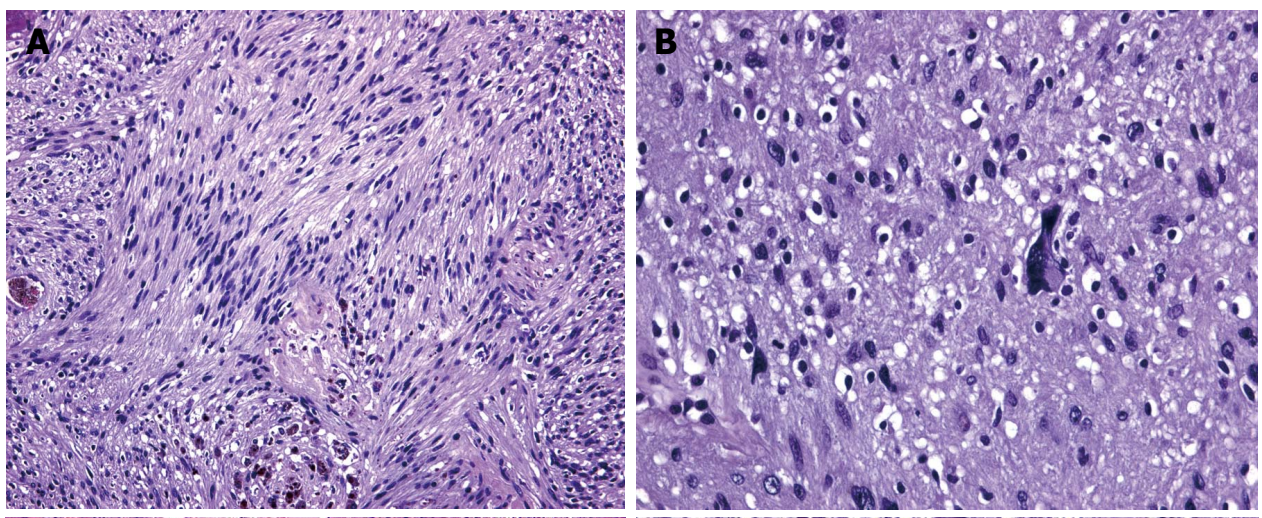

Figure 3 A: Histological examination showing that inter-woven bundles of fused cells separated by slacker, oedematous areas with a pseudocystic appearance (Antoni A schwannoma growth pattern); B: Histological examination showing a few cells with hyperchromic, atypical and bizarre nuclei.Histological examination showing a few cells with hyperchromic, atypical and bizarre nuclei; $\mathbf{C}$ : Histological examination showing hyalinisation and ectatic and partially thrombosed vessels; D: Histological examination showing
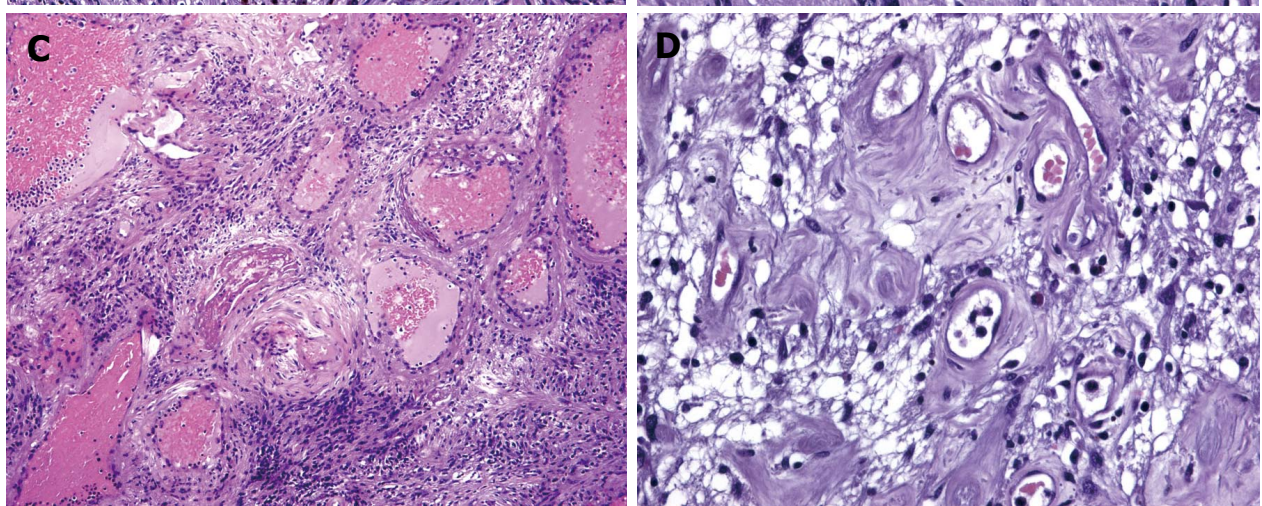
perivascular hyalinisation.

Liver, rectal colon and esophageal involvement has been described $^{[11-14]}$, whereas only nine cases of schwannoma of the extrahepatic biliary tract and one case of benign schwannoma in the hepatoduodenal ligament have been reported since the $1970 \mathrm{~s}^{[7,15-23]}$. Determination of tumor location must be done with great care when mass exists between the liver and the retroperitoneum, especially when the mass is hypovascular. Pre-surgical diagnosis of the tumor is very difficult because early clinical detection is limited until it gives a palpable mass or compresses the surrounding organs ${ }^{[6]}$.

Diagnosis is usually entrusted to CT and MRI. The gastrointestinal schwannomas appeared as a round or oval homogeneously attenuating, well-defined mass with frequent signs of degeneration, such as cysts and calcifications on $\mathrm{CT}^{[24]}$. Recently it was reported that CTs do not reveal tumor capsule, cystic change, necrosis or calcification in any of the observed schwannomas ${ }^{[25]}$. Weighted T1 images disclose masses with low-medium signal intensity, whereas this is high in the weighted T2 images owing to alternation of the Antoni A and B areas and secondary degeneration ${ }^{[26]}$.

In the present case, CT illustrated a hypodense and very heterogeneous formation initially referable to duodenal diverticulum. The MRI images were marked by slight weighted T2 hyperintensity due to the partially fluid content. A good response to secretin showed that the function of the pancreas was unimpaired.

We did not employ PET with fluorodeoxyglucose (FDG) uptake since it has been widely used to quantify the metabolism of malignant bone and soft-tissue malignant tumors, whereas little is known about FDG uptake in benign lesions. FDG PET is of limited value for the preoperative differentiation of schwannoma versus sarcoma ${ }^{[27]}$. Thus, a high FDG uptake is rather common in schwannoma ${ }^{[28]}$.

The macroscopic growth pattern of the tumor mass was atypical. The two schwannoma growth patterns are called Antoni A and Antoni B. Elongated cells form an irregular, but compact palisade and the tissue arrangement is loose and there are cystic spaces between the cells ${ }^{[2]}$. In some cases, insufficient vascularisation of the mass may lead to degeneration in the form of cysts, calcifications, haemorrhages and hyalinisation ${ }^{[30]}$. These degenerative tumors are called "ancient schwannomas". Morphologic and immunophenotypic features of the lesion pointed to a so-called "ancient schwannoma", with reactive lymph nodes as described in the literature ${ }^{[31]}$. Digestive tract schwannomas are different from their soft tissue counterpart; they are not encapsulated and have an intramural growth pattern. Moreover, they are different both histologically and immunohistochimically from peripheral schwannomas. Gastrointestinal schwannomas, as in our case, are usually negative for CD34, CD117 and muscle cell markers, whereas they are strongly positive for vimentin and S100 protein. This typical combination differentiates schwannomas of the digestive tract from GIST. This differentiation is of practical importance. Gastrointestinal schwannomas are benign and associated with a good prognosis since post-surgical recurrences are unusual ${ }^{[32]}$, even when treated only with enucleation. Gastrointestinal stromal tumors, on the other hand, present a negative course in more than $50 \%$ of the cases $^{[33,34]}$.

The distinctive feature of this case is the complexity of its diagnosis. Conventional radiography was unable to provide a precise picture of the nature and location of the mass. A diagnosis deduced from the instrumental finding often awaits intraoperative and definitive histological 
confirmation $^{[6]}$. Despite its complications, resection remains the treatment of choice. In the present case, only explorative laparotomy was able to demonstrate the seat and the nature of the lesion.

Lastly, in our case the postoperative course was uneventful and the cholestatic symptoms regressed two months after the operation.

\section{REFERENCES}

1 Reed JC, Hallet KK, Feigin DS. Neural tumors of the thorax: subject review from the AFIP. Radiology 1978; 126: 9-17

2 Kim SH, Choi BI, Han MC, Kim YI. Retroperitoneal neurilemoma: CT and MR findings. AJR Am J Roentgenol 1992; 159: 1023-1026

3 Shields TW, Reynolds M. Neurogenic tumors of the thorax. Surg Clin North Am 1988; 68: 645-668

4 MacCollin M, Chiocca EA, Evans DG, Friedman JM, Horvitz R, Jaramillo D, Lev M, Mautner VF, Niimura M, Plotkin SR, Sang $\mathrm{CN}$, Stemmer-Rachamimov A, Roach ES. Diagnostic criteria for schwannomatosis. Neurology 2005; 64: 1838-1845

5 Prévot S, Bienvenu L, Vaillant JC, de Saint-Maur PP. Benign schwannoma of the digestive tract: a clinicopathologic and immunohistochemical study of five cases, including a case of esophageal tumor. Am J Surg Pathol 1999; 23: 431-436

6 de Diego Rodríguez E, Roca Edreira A, Martín García B, Hernández Rodríguez R, Portillo Martín JA, Gutiérrez Baños JL, Correas Gómez MA, del Valle Schaan JI, Villanueva Peña A, Rado Velázquez MA, Torío Sánchez B. Retroperitoneal benign schwannoma. Report of a new case. Actas Urol Esp 2000; 24: 685-688

7 Honjo Y, Kobayashi Y, Nakamura T, Takehira Y, Kitagawa M, Ikematsu Y, Ozawa T, Nakamura H. Extrahepatic biliary schwannoma. Dig Dis Sci 2003; 48: 2221-2226

8 Das Gupta TK, Brasfield RD, Strong EW, Hajdu SI. Benign solitary Schwannomas (neurilemomas). Cancer 1969; 24: 355-366

9 Lane RH, Stephens DH, Reiman HM. Primary retroperitoneal neoplasms: CT findings in 90 cases with clinical and pathologic correlation. AJR Am J Roentgenol 1989; 152: 83-89

10 Kinoshita T, Naganuma H, Ishii K, Itoh H. CT features of retroperitoneal neurilemmoma. Eur J Radiol 1998; 27: 67-71

11 Daimaru Y, Kido H, Hashimoto H, Enjoji M. Benign schwannoma of the gastrointestinal tract: a clinicopathologic and immunohistochemical study. Hum Pathol 1988; 19: 257-264

12 Wada Y, Jimi A, Nakashima O, Kojiro M, Kurohiji T, Sai K. Schwannoma of the liver: report of two surgical cases. Pathol Int 1998; 48: 611-617

13 Fotiadis CI, Kouerinis IA, Papandreou I, Zografos GC, Agapitos G. Sigmoid schwannoma: a rare case. World J Gastroenterol 2005; 11: 5079-5081

14 Nagai T, Fujiyoshi K, Takahashi K, Torishima R, Nakashima H, Uchida A, Ookawara H, Fujitomi Y, Suzuki K, Yokoyama S, Sato R, Murakami K, Fujioka T. Ileal schwannoma in which blood loss scintigraphy was useful for diagnosis. Intern Med 2003; 42: 1178-1182
15 Wiermann H, Wienbeck M. Benign tumors as the cause of extrahepatic occlusion syndrome. Report on a neuroma of the bile ducts. Z Gastroenterol 1975; 13: 685-689

16 Whisnant JD, Bennett SE, Huffman SR, Weiss DL, Parker JC, Griffen WO. Common bile duct obstruction by granular cell tumor (schwannoma). Am J Dig Dis 1974; 19: 471-476

17 Silvestri F. Neuroma of the common bile duct stump. Chir Ital 1965; 17: 19-75

18 ODEN B. Neurinoma of the common bile duct; report of a case. Acta Chir Scand 1955; 108: 393-397

19 Ronchetti A, Zanniello JM. Schwannoma of the common bile duct. Comments on a case. Dia Med 1962; 34: 1365-1371

20 Balart LA, Hines C, Mitchell W. Granular cell schwannoma of the extrahepatic biliary system. Am J Gastroenterol 1983; 78: 297-300

21 Jakobs R, Albert J, Schilling D, Nuesse T, Riemann JF. Schwannoma of the common bile duct: a rare cause of obstructive jaundice. Endoscopy 2003; 35: 695-697

22 Park MK, Lee KT, Choi YS, Shin DH, Lee JY, Lee JK, Paik SW, Ko YH, Rhee JC. A case of benign schwannoma in the porta hepatis. Korean J Gastroenterol 2006; 47: 164-167

23 Häring RU, Waninger J, Farthmann EH. Abdominal surgery in advanced age. Indications and prognosis exemplified by stomach, bile duct, colon and hernia surgery. Fortschr Med 1993; 111: 98-101

24 Rha SE, Byun JY, Jung SE, Chun HJ, Lee HG, Lee JM. Neurogenic tumors in the abdomen: tumor types and imaging characteristics. Radiographics 2003; 23: 29-43

25 Levy AD, Quiles AM, Miettinen M, Sobin LH. Gastrointestinal schwannomas: CT features with clinicopathologic correlation. AJR Am J Roentgenol 2005; 184: 797-802

26 Sakai F, Sone S, Kiyono K, Maruyama A, Ueda H, Aoki J, Kawai T, Ishii K, Morimoto M, Haniuda M. Intrathoracic neurogenic tumors: MR-pathologic correlation. AJR Am J Roentgenol 1992; 159: 279-283

27 Ahmed AR, Watanabe H, Aoki J, Shinozaki T, Takagishi K. Schwannoma of the extremities: the role of PET in preoperative planning. Eur J Nucl Med 2001; 28: 1541-1551

28 Beaulieu S, Rubin B, Djang D, Conrad E, Turcotte E, Eary JF. Positron emission tomography of schwannomas: emphasizing its potential in preoperative planning. AJR Am J Roentgenol 2004; 182: 971-974

29 Rosai J. Ackerman's surgical pathology. 6th ed. St. Louis, Mo: Mosby-Year Book, 1981: 1407-1479

30 Enzinger FM, Weiss SW. Soft tissue tumors. 2nd ed. St Louis, Mo: Mosby-Year Book, 1988: 719-860

31 Hou YY, Tan YS, Xu JF, Wang XN, Lu SH, Ji Y, Wang J, Zhu XZ. Schwannoma of the gastrointestinal tract: a clinicopathological, immunohistochemical and ultrastructural study of 33 cases. Histopathology 2006; 48: 536-545

32 Ben Moualli S, Hajri M, Ben Amna M, Kolsi K, Chebil M, Ben Jilani S, Zaouech A, Ayed M. Retroperitoneal schwannoma. Case report. Ann Urol (Paris) 2001; 35: 270-272

33 Duffaud F, Blay JY. Gastrointestinal stromal tumors: biology and treatment. Oncology 2003; 65: 187-197

34 Tran T, Davila JA, El-Serag HB. The epidemiology of malignant gastrointestinal stromal tumors: an analysis of 1,458 cases from 1992 to 2000. Am J Gastroenterol 2005; 100: 162-168

S- Editor Liu Y L- Editor Ma JY E- Editor Zhou T 